\title{
Faktor Penyebab Rendahnya Jumlah Pria dalam Mendukung Penggunaan Alat Kontrasepsi
}

\author{
Nurlina Subair ${ }^{1}$, Risma Haris ${ }^{2 *}$, Syahban Nur ${ }^{1}$ \\ ${ }^{1}$ Program Studi Pendidikan Sosiologi, Fakultas Keguruan dan Ilmu Pendidikan \\ Universitas Muhammadiah Makassar \\ subairnurlina@gmail.com \\ ${ }^{2}$ Program Studi Kesehatan Lingkungan, Fakultas Kesehatan Masyarakat \\ Universitas Indonesia Timur \\ arismarifin@gmail.com
}

\begin{abstract}
.
This study aims to determine the factors that cause the low number of men who support the use of contraception in order to improve the quality of family welfare. This quantitative descriptive research method was analyzed descriptively on 86 respondents who were observed and interviewed clinically to obtain data on the factors causing the low number of men who supported the use of contraception. The results of the study revealed that from 86 respondents, according to his knowledge that men who did not use contraception with good knowledge were 25 people (29\%), men who did not use contraception with enough knowledge were 44 people (51\%), and men who did not use the tools contraception with less knowledge as many as 18 people (20\%). According to the attitude there are 28 (32\%) who agree and 43 people (49\%) who disagree, this can be concluded that men assess the use of contraception is very necessary, but not a few of the men who do not agree. This was triggered because of the inherent paradigm that the use of contraceptives was only too long for women.
\end{abstract}

Keywords: causative factors, men, contraception

\section{PENDAHULUAN}

Laju pertumbuhan penduduk pun makin dunia meningkat tiap tahunnya. Dalam penelitian Rahadiati dkk (2018) menjelaskan bahwa pertumbuhan penduduk dipengaruhi oleh kelahiran, kematian dan migrasi. Permasalahan pertumbuhan penduduk sejatinya dapat ditekan dengan adanya program Keluarga Berencana (KB). Pemahaman akan penggunaan alat kontrasepsi telah disosialisasikan oleh pemerintah sampai ditingkat RT/RW. Namun, terdapat berbagai kedala dalam pelaksanaannya yang terkadang menimbulkan perbedaan persepsi antara masyarakat maupun keluarga khususnya para kepala keluarga atau suami itu sendiri.

Hal ini disebabkan informasi yang diperoleh dari kecanggihan teknologi terkadang membuat mereka mengambilnya tanpa memfilter. Banyak sekali hal-hal yang berkaitan dengan hal ini, mulai dari pemahaman mengenai jenis - jenis alat kontrasepsi, pemahaman mengenai prosedur penggunaan alat kontrasepsi serta manfaat dan dampaknya terhadap kualitas kesejahteraan keluarga.

Sejak tahun 2001 pemerintah Indonesia telah mulai melaksanakan pembangunan yang berorientasi pada kesetaraan dan keadilan gender, namun demikian sampai saat ini permasalahan utama yang kita hadapi adalah rendahnya jumlah pria yang turut serta dalam pelaksanaan program KB dan Kesehatan Reproduksi. Menurut Wahyuni dkk (2013) Bentuk dukungan pria dalam KB adalah kesertaan ber-KB, serta berperilaku seksual yang sehat dan aman bagi dirinya, pasangan dan keluarganya. Beberapa metode pencegahan kehamilan bagi pria seperti kondom, vasektomi, senggama terputus atau metode pantang berkala.

Pencapaian pelaksanaan program KB dapat dikatakan berhasil dengan adanya peningkatan jumlah Pasangan Usia Subur (PUS) dalam ber KB. Namun terdapat ketimpangan dalam jumlah pengguna alat kontrasepsi pada Pasangan Usia Subur (PUS) antara Wanita dan Pria. Menurut data status pemakaian kontrasepsi tahun 2017 masih terdapat 36,4\% masyarakat Indonesia yang tidak 
menggunakan alat kontrasepsi. Partisipasi pria dalam ber KB masih sangat rendah di Indonesia masih dibawah $8 \%$ dari yang ditargetkan pemerintah.

Hal tersebut menjadi dasar pentingnya penelitian ini, Secara umum penelitian ini bertujuan untuk mengetahui faktor penyebab rendahnya jumlah pria yang mendukung penggunaan alat kontrasepsi dalam rangka meningkatkan kualitas kesejahteraan keluarga.

\section{METODE}

\section{Jenis Penelitian}

Penelitian ini bersifat kuantitatif deskriptif yakni untuk mengetahui gambaran faktor-faktor penyebab rendahnya jumlah pria yang menggunakan alat kontrasepsi di Kelurahan Parangtambung Kecamatan Tamalate Kota Makassar. Penelitian ini dilaksanakan pada tanggal 20 September 2018, yang dimulai dari melakukan izin penelitian, survei penelitian, pengolahan hasil penelitian dan penyusunan laporan penelitian. Lokasi penelitian yang dipilih adalah Kelurahan Parangtambung Kecamatan Tamalate Kota Makassar. Adapun alasannya karena memenuhi sampel dan mempunyai data yang lengkap sehingga lebih memudahkan peneliti mengumpulkan data serta mendukung dalam menyusun laporan penelitian ini. Penarikan sampel yaitu PUS yang tidak menggunakan alat kontrasepsi dengan jumlah sampel sebanyak 87 orang. Teknik pengambilan sampel menggunakan purposive sampling.

\section{Identifikasi Variabel dan Instrumen Penelitian}

Variabel bebas yaitu; pengetahuan dan sikap sedangkan Variabel terikat yaitu; rendahnya jumlah pria pengguna alat kontrasepsi. Sedangkan Instrumen yang digunakan dalam penelitian ini adalah format pengumpulan data yaitu kuesioner dan pedoman wawancara.

\section{HASIL DAN PEMBAHASAN}

\section{Karakteristik Responden}

Hasil pra penelitian diperoleh dari puskesmas kelurahan parangtambung yang dapat dilihat dalam tabel 1 bahwa terdapat 4.305 Pasangan Usia Subur (PUS).

Tabel 3.1 Data Peserta Pasangan Usia Subur pengguna Kontrasepsi

\begin{tabular}{cc}
\hline Data & Jumlah Peserta \\
\hline MOW & 108 \\
MOP & 54 \\
IUD & 539 \\
IMPLAN & 483 \\
SUNTIK & 1387 \\
PIL & 369 \\
KONDOM & 225 \\
Total Peserta & 4.305 \\
\hline
\end{tabular}

Sumber: Puskesmas Parangtambung, 2018

Penggunaan alat kontrasepsi saat ini masih didominasi oleh para wanita, hanya terdapat 54 perserta pria pengguna MOP dan 225 peserta pria pengguna KONDOM. Padahal jumlah penduduk di kelurahan Parangtambung menurut tabel 3.2 yang di kelompokkan sesuai dengan Tahapan Keluarga Sejahtera berikut;

Tabel 3.2 Jumlah Pendudukan menurut Tahapan Sejahtera

\begin{tabular}{cc}
\hline Tahapan Keluarga Sejahtera & Jumlah Peserta \\
\hline Pra Sejahtera & 1.993 \\
Sejahtera 1 & 1.326 \\
Sejahtera 2 & 3.794 \\
Total Penduduk & 7.113 \\
\hline
\end{tabular}

Data diatas mengungkapkan bahwa jumlah penduduk kelurahan parangtambung berjumlah 7.113 yang terbagi atas Pra sejahtera, sejahtera 1 dan sejahtera 2. Jika dilihat dari data diatas mengungkapkan rendahnya jumlah pengguna alat kontrasepsi dikelurahan tersebut. 
Sehingga dalam upaya membantu meningkatkan jumlah pengguna alat kontrasepsi pada Pasangan Usia Subur (PUS) khususnya Pria. Kemudian menjadi penting untuk mengetahui faktor yang menjadi penyebab rendahnya jumlah pria yang mendukung penggunaan alat kontrasepsi. Faktor - faktor yang terkait seperti pengetahuan, sikap, dukungan keluarga, faktor budaya, ketersediaan, keterjangkauan pelayanan dan dukungan dari petugas pelayanan KB di kelurahan parangtambung Kota Makassar. Upaya tersebut diharapkan menjadi salah satu upaya meningkatkan pencapaian peserta KB di Kelurahan - kelurahan lainnya di Kota Makassar. Dalam proses penelitian tersebut, maka dibutuhkan bantuan, kerjasama maupun kemitraan antara MC3, puskesmas, kelurahan, kecamatan pemerintah kotada dan provinsi Khususnya disini BKKBN.

\section{Hasil Penelitian}

Penelitian dilakukan pada bulan September - Desember 2018 di Kelurahan Parangtambung Kecamatan Tamalate Kota Makassar. Gambaran Faktor penyebab rendahnya jumlah pria yang mendukung penggunaan alat kontrasepsi tahun 2018, maka diperoleh hasil penelitian berdasarkan pengetahuan dan sikap.

\section{Pengetahuan}

Hasil penelitian disajikan dalam beberapa bentuk tabel distribusi yang terdiri dari analisis univariat sebagai berikut :

Tabel 3.3 Distribusi Frekuensi Gambaran Faktor penyebab rendahnya pria menggunakan alat kontrasepsi di Kelurahan Parangtambung Kecamatan Tamalate tahun 2018

\begin{tabular}{|c|c|c|c|}
\hline \multirow{2}{*}{ No } & \multirow{2}{*}{ Pengetahuan } & \multicolumn{2}{|c|}{ Jumlah } \\
\hline & & F (orang) & Persentase (\%) \\
\hline 1 & $\begin{array}{l}\text { Baik (responden menjawab sebanyak } \\
75-100 \%)\end{array}$ & 25 & 29 \\
\hline 2 & $\begin{array}{l}\text { Cukup (responden menjawab sebanyak } \\
56-75 \% \text { ) }\end{array}$ & 44 & 51 \\
\hline 3 & $\begin{array}{c}\text { Kurang (responden menjawab sebanyak } \\
<55 \% \text { ) }\end{array}$ & 18 & 20 \\
\hline & Jumlah & 87 & 100 \\
\hline
\end{tabular}

Sumber: Data Primer

Berdasarkan hasil analisis penilaian tabel 3.3 diketahui bahwa jumlah pria yang tidak menggunakan alat kontrasepsi berjumlah 87 , adapun pria yang tidak menggunakan alat kontrasepsi dengan pengetahuan baik sebanyak 25 orang $(29 \%)$, pria yang tidak menggunakan alat kontrasepsi dengan pengetahuan cukup sebanyak 44 orang (51\%), dan pria yang tidak menggunakan alat kontrasepsi dengan pengetahuan kurang sebanyak 18 orang (20\%).

Sikap

Hasil penelitian mengenai faktor penyebab rendahnya pria menggunakan alat kontrasepsi berdasarkan sikap dapat dilihat pada tabel berikut ini:

Tabel 3.4 Distribusi Frekuensi Gambaran Faktor penyebab rendahnya pria menggunakan alat kontrasepsi di Kelurahan Parangtambung Kecamatan Tamalate tahun 2018

\begin{tabular}{|c|c|c|c|}
\hline \multirow{2}{*}{ No } & \multirow{2}{*}{ Sikap } & \multicolumn{2}{|c|}{ Jumlah } \\
\cline { 3 - 4 } & Setuju Setuju & 16 & 18 \\
\hline 1 & Setuju & 28 & 32 \\
\hline 2 & Tidak Setuju & 43 & 49 \\
\hline 3 & Jumlah & 87 & 100 \\
\hline \multicolumn{2}{|l}{} \\
\hline
\end{tabular}

Sumber: Data Primer

Berdasarkan hasil analisis penilaian sikap tabel 3.4 diketahui bahwa jumlah pria yang tidak menggunakan alat kontrasepsi berjumlah 87 , adapun pria yang memiliki sikap sangat setuju sebanyak 16 orang (18\%), pria yang memiliki sikap setuju sebanyak 28 orang $(32 \%)$, dan pria yang memiliki sikap tidak setuju sebanyak 43 orang (49\%). 


\section{Pembahasan}

Faktor penyebab rendahnya jumlah pria yang menggunakan alat kontrasepsi berdasarkan pengetahuan.

Pengetahuan merupakan hasil pengindraan manusia, atau hasil tahu seseorang terhadap objek melalui indra yang dimilikinya seperti mata, hidung, telinga dan sebagainya (Zulkifli,2018). Pengetahuan merupakan informasi yang dapat mengubah seseorang, hal itu terjadi ketika informasi tersebut menjadi dasar untuk bertindak (Alam, 2018). Berdasarkan tabel 4 diperoleh hasil bahwa dari 86 responden sebagian besar memiliki pengetahuan cukup sebesar 44 responden $(51 \%)$. Penyebab jumlah pria memiliki pengetahuan cukup tentang penggunaan alat kontrasepsi dapat disebabkan karena beberapa hal yaitu; (1) Kurangnya edukasi yang dilakukan tenaga kesehatan (pegawai atau kader puskesmas) terhadap pria tentang penggunaan alat kontrasepsi yang dapat digunakan, tenaga kesehatan lebih cenderung memberikan edukasi terhadap wanita dalam hal penggunaan alat kontrasepsi tersebut; (2) Minimnya sumber Informasi tentang manfaat, keamanan dan kenyaman dalam penggunaan alat kontrasepsi bagi pria. Serta sebagian besar pria masih mempercayai bahwa penggunaan alat kontrasepsi merupakan tanggung jawab kaum wanita, sehingga sebagian besar dari pria lebih memilih mengikuti riwayat penggunaan alat kontrasepsi turun temurun yang telah digunakan terdahulu yang dianggap berhasil.

Beberapa pria tidak menggunakan alat kontrasepsi percaya bahwa kontrasepsi yang dipergunakan kaum wanita saat ini sudah sangat efektif penggunaannya. Para pria juga kurang mengetahui tentang tingkat keamanan penggunaan alat kontrasepsi pria serta kenyamanan dalam berinteraksi dengan pasangannya. Penelitian yang telah dilakukan ini sejalan dengan penelitian Sutinah tahun 2017 dengan judul partisipasi pria dalam keluarga berencana di Madiun Jawa Timur tahun 2017 diperoleh jumlah sampel penelitian adalah 75 responden pria yang dipilih secara purposif. Hasil penelitian diperoleh sebanyak $44 \%$ memiliki pengetahuan cukup yang disebabkan kurang mengikuti sosialisasi. Untuk itu diharapkan para petugas/ kader puskesmas lebih meningkatkan pemberian penyuluhan maupun konseling kepada pasangan usia subur khususnya para suami tentang alat kontrasepsi yang dapat digunakan oleh para pria, namun harus tepat sasaran dan benar dalam pelaksanaannya.

Faktor penyebab rendahnya jumlah pria yang menggunakan alat kontrasepsi berdasarkan sikap.

Menurut Lesmana (2018) Sikap merupakan produk dari proses sosialisasi yang telah diberikan sehingga seseorang bereaksi sesuai dengan rangsang yang telah diterimanya. Reaksi atau respons seseorang yang masih tertutup terhadap stimus dianggap wajar, jika informasi yang diperoleh tidak sampai secara benar dan tepat. Penilaian sikap seseorang dapat dilihat sejauh mana mereka berpendapat saat ini (Aminah,2018).

Dari hasil penelitian dapat diketahui dari 86 responden, terdapat 28 (32\%) yang setuju dan 43 orang (49\%) yang tidak setuju, hal ini dapat disimpulkan bahwa pria menilai penggunaan alat kontrasepsi sangatlah diperlukan, namun tidak sedikit dari para pria yang tidak setuju. Adapun penyebab pria tidak setuju menggunakan alat kontrasepsi disebabkan oleh; (1) Tabu, sikap pria terhadapat alat kontrasepsi yang akan digunakan pada beberapa pria mengalami kekhawatiran dikarenakan munculnya perasaan malu. Hal ini dipicu karena paradigma yang melekat terlalu lama bahwa penggunaan alat kontrasepsi hanya dilakukan oleh para wanita saja; (2) Potensi seksual pria, sebanyak $31 \%$ responden (pria/suami) menyatakan bahwa penggunaan alat kontrasepsi pria itu beresiko pada kemampuan seksual pria, khususnya vasektomi. Vasektomi menurut responden dapat membuat impoten sehingga banyak dari kaum pria enggan menggunakannya.

Hal ini sejalan dengan Penelitian yang telah dilakukan oleh Sutinah tahun 2017 dengan judul partisipasi pria dalam keluarga berencana di Madiun Jawa Timur tahun 2017 diperoleh jumlah sampel penelitian adalah 75 responden pria yang dipilih secara purposif. Hasil penelitian diperoleh sebanyak $36 \%$ responden khawatir dalam melakukan alat kontrasepsi pria karena khawatir mempengaruhi 
kejantanan dan interaksi sosial yang masih menggangap alat kontrasepsi pria sesuatu yang diluar kebiasaan orang timur.

\section{KESIMPULAN DAN SARAN \\ Kesimpulan}

Adapun hasil penelitian faktor penyebab rendahnya jumlah pria yang mendukung penggunaan alat kontrasepsi dalam rangka meningkatkan kualitas kesejahteraan keluarga., maka peneliti menyimpulkan bahwa:

1. faktor penyebab rendahnya pria menggunakan alat kontrasepsi berdasarkan pengetahuan, mayoritas pria memiliki pengetahuan yang cukup sebanyak 44 orang $(51 \%)$.

2. faktor penyebab rendahnya pria menggunakan alat kontrasepsi berdasarkan sikap, mayoritas pria kurang setuju sebanyak 43 orang (49\%).

\section{Saran}

Bagi Peneliti selanjutnya agar dapat meneliti lebih mendalam tentang faktor penyebab rendahnya jumlah pria yang menggunakan alat kontrasepsi dengan mengembangkan beberapa metode yang mempengaruhi perubahan perilaku masyarakat untuk menghasilkan sebuah strategi atau kebijakan dalam rangka meningkatkan kualitas kesejahteraan keluarga.

\section{UCAPAN TERIMAKASIH}

Penulis mengucapkan terima kasih kepada BKKBN Provinsi Sulawesi Selatan yang telah memberi dukungan financial terhadap penelitian ini.

\section{REFERENSI}

Alam, P.F., Fajrillah, A.A.N., Azizah, A.H. and Almaarif, A., 2018. Perancangan Model Tata Kelola Pengetahuan Proses Inovasi Produk Pada Techno Park. Jurnal Ilmiah Teknologi Informasi Terapan, 4(2).

Aminah, S., 2018. Pengetahuan Dan Sikap Keluarga Dalam Pelaksanaan Perilaku Hidup Bersih Dan Sehat Di Wilayah Kerja Puskesmas Sombaopu Gowa. Media Keperawatan: Politeknik Kesehatan Makassar, 9(1), pp.39-52.

Lesmana, D., Panjaitan, D. and Maimunah, M., 2018. Tax Compliance Ditinjau dari Theory of Planned Behavior (TPB): Studi Empiris Pada Wajip Pajak Orang Pribadi dan Badan yang Terdaftar Pada KPP di Kota Palembang. InFestasi, 13(2), pp.354-366.

Rahadiati, A., Yuliana, E., Hafsaridewi, R., Khairuddin, B., Kusuma, L. P. A. S. C., Angin, R. P.,\& Adibrata, S. 2018. Model Spasial Temporal Dampak Kenaikan Muka Air Laut Terhadap Permukiman Penduduk Di Pulau Kecil (Kasus: Pulau Karimunjawa Dan Pulau Kemujan, Kabupaten Jepara). Jurnal Matematika Sains dan Teknologi, 19(2), 138-151.

Sutinah, S., 2017. Partisipasi laki-laki dalam program Keluarga Berencana di era masyarakat postmodern. Masyarakat, Kebudayaan dan Politik, 30(3), pp.290-299.

Wahyuni, N.P.D.S., Suryani, N. and Murdani, K., 2013. Hubungan Pengetahuan dan Sikap Akseptor KB Pria tentang Vasektomi serta Dukungan Keluarga dengan Partisipasi Pria dalam Vasektomi (Di Kecamatan Tejakula Kabupaten Buleleng). Jurnal Magister Kedokteran Keluarga, 1(1), pp.80-91.

Zulkifli, Z., Bakhri, B.S. and Yusuf, M., 2018. Analisis Pengetahuan Masyarakat Kota Pekanbaru tentang Wisata Syariah. Al-Hikmah: Jurnal Agama dan Ilmu Pengetahuan, 15(2), pp.84-103. 